\title{
Assessing the Enablers and Barriers to Quality and Supply Chain Management Based Approach to Sustainable Operations in the Manufacturing Context
}

\author{
Ali Bastas ${ }^{a}$ and Kapila Liyanage ${ }^{b, 1}$ \\ ${ }^{a}$ Department of Industrial Engineering, Eastern Mediterranean University, 99628, \\ Famagusta, North Cyprus via Mersin 10, Turkey \\ ${ }^{\mathrm{b}}$ College of Science and Engineering, University of Derby, United Kingdom \\ aali.bastas@emu.edu.trbk.liyanage@derby.ac.uk
}

\begin{abstract}
Sustainability is becoming the prominent concept of focus for manufacturing research and practice. Various research streams are endeavouring to facilitate its integration and implementation to manufacturing organisations including approaches that use quality management and supply chain management. Sustainability integration is a complex matter for the manufacturing industry, identification of associated enablers and barriers proving fruitful to catalyse the transition of manufacturing organisations into sustainable operations and management practices. This research investigated the enablers and barriers to quality and supply chain management based integration of sustainability in manufacturing organisations through a focussed action research study. The key factors were noted as; integration to existing management systems and processes, familiarity and awareness level of sustainability concepts and terminology, absence of a minimum starter package for Global Reporting Initiative (GRI) sustainability reporting standards, resource constraints, leverage over supply base, culture and human resource limitations, willingness to learn, commitment, support and engagement of leadership, management system maturity, change facilitation and championing, governmental subsidisation and support, and sustainability awareness of public and market.
\end{abstract}

Keywords. Sustainability, Quality Management, Supply Chain Management, Manufacturing Industry.

\section{Introduction}

Sustainability, which is articulated as the multi-dimensional, triple-bottom line (TBL) concept in the organisational perspective [1], is exponentially growing in importance for manufacturing organisations [2]. There are various challenges associated with integration of sustainability into management processes [3], including the resource requirement and complexity of satisfying conflicting agendas inherent in economic, environmental and social considerations [4], and requirement of a clear approach to guide manufacturing managers in its effective and productive implementation [5]. Sustainable manufacturing is key to achieving sustainable development [6], supporting achievement of UN's Sustainable Development Goals [7], especially the responsible consumption and production goal.

\footnotetext{
${ }^{1}$ Kapila Liyanage, College of Science and Engineering, University of Derby, Markeaton Street, Derby,
} DE22 3AW, United Kingdom, E-mail: K.Liyanage@derby.ac.uk 
Quality management (QM) is an organisational excellence discipline, acting as a key framework for continuous improvement of manufacturing organisations [8]. Evidence in the literature suggests its principles and methodologies to be complementary and to be in synergy with sustainability implementation in organisations [9], [10]. Supply chain management (SCM), which is the key management discipline that coordinates the intra and interorganisational activities of manufacturing firms, is another avenue that is adopted to facilitate sustainable development of manufacturing organisations [2], [11], [12]. Integrated, QM and SCM based approach to sustainability implementation and improvement was evidenced [13], conceptualised [14], and implemented in the manufacturing context [15] under the framework of Sustainable Supply Chain Quality Management (SSCQM).

Enablers and barriers to sustainability implementation in organisations were investigated by various contributions to date [16]-[18], however, many research gaps are still present, including a detailed focus on the manufacturing industry, and identification of factors specific to a QM and SCM based approach to integration of sustainability in manufacturing organisations. Thus, the objective of this study was to investigate in detail, the enablers, barriers and other contextual factors for operationalisation of SSCQM.

Barriers in the context of implementing an organisational phenomenon are identified by Giunipero et al. (2012) [19], as “factors that hinder a firm's effort to adopt the change and associated new practice". Enablers in the business management practice context, which are also referred to as "drivers", are articulated as following by Neri et al. (2018) [17]:

Enabler: "The opposite of a barrier or a mean to overcome barriers, that can be both internal and external in origin, with reference to the organisation, promoted by one or more stakeholders with impact on the business and managerial decision making processes."

\section{Methodology}

The methodology adopted in this research is action research, where the integrated QM and SCM based approach to sustainability (referred to as SSCQM [13]), utilising GRI as its main sustainability measurement and reporting mechanism [20], [21], was implemented at a manufacturing organisation, operating at the Northern Cyprus industry. The key advantages of action research study includes gathering of new information and development of insights with reference to phenomena under investigation, introducing changes in the context being studied [22], and immersive observation of the phenomena of interest in its particular context [23], [24].

The manufacturing organization that took part in the study, was studied during the implementation and validation of SSCQM framework [15], which is an engineering and distribution firm, manufacturing chemical and construction materials such as paint, concrete preparation and insulation materials. A wide level of engagement was achieved during the action research study, interacting with the employees of the manufacturing entity at all levels including the managing director, middle managers, supervisors and operators, representing the views and input from all layers of the manufacturing organisation [15].

The participative observation and discussion method [25], [26]; was applied during the assessment of enablers, barriers and other contextual factors important to operationalisation of a QM and SCM based approach to sustainability. Each factor 
observed and noted during application were not classified specifically as an enabler or a barrier as this would depend on the absence/presence of each parameter in the specific context of application e.g. the presence of management system maturity in the specific context of application being classed as an enabler, and the absence of the same being classed as a barrier or challenge for implementation of the framework. For consistency, and due to its established strengths in analysis of qualitative information collected and structured generation of key themes, the thematic synthesis method was adopted for establishment of key information within the qualitative data captured [27].

\section{Results}

The observations made regarding the enablers, barriers and challenges to QM and SCM based sustainable development approach (SSCQM) were schematically demonstrated in Figure 1, and were categorised into the following main themes:

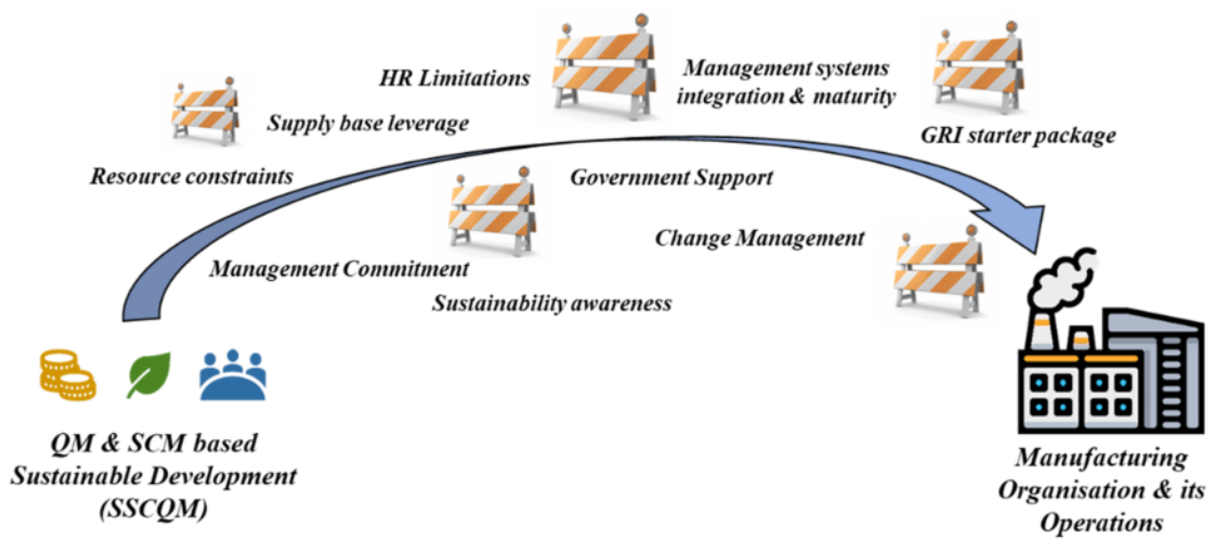

Figure 1: Enablers and Barriers of SSCQM in the Manufacturing Context

Integration to existing management systems and processes: One of the primary challenges observed during the implementation of SSCQM approach was the issue of changing, updating, revising and rebuilding the existing management processes including the quality management system for incorporation of sustainability parameters. It was noted that the participating business did already invest a high level of resources into their quality management system and the adoption of SSCQM philosophy implied further changes, which was initially faced with reluctance. However, the flexible IT system in place, the continuous improvement culture, research and development capabilities, and the accommodating approach of most team members in the organisation were observed as remarkable factors for managing and mitigating the effect of this barrier.

Familiarity and awareness level of sustainability concepts and terminology: Sustainability being a relatively new concept, especially in the Cyprus region, brought together a low level of familiarity, awareness and competence in the organisational leadership and team members regarding the sustainability concepts, indicators, the GRI framework and associated terminology, which was experienced as another remarkable challenge during the application phase. A number of brief training sessions were held by the researcher among various internal stakeholder groups of the organisation for establishment of effective communications, clarification of expectations, articulation of 
standard definitions and alignment of perceptions regarding the key sustainability concepts, main terminologies and the GRI framework.

Absence of a minimum starter package for GRI: During the stakeholder analysis and identification of sustainability priorities, a comprehensive review was undertaken, studying in detail, each and every GRI indicator, which consumed a remarkable time and effort of both the researcher and more importantly the organisational strategic leadership. Due to the high level of new terminology involved as outlined in the previous point, and the high number of GRI sustainability indicators involved (e.g. 19 indicators for social dimension) led to a significant resistance and acted as a fear factor at the leadership of the participating organisation. On the other hand, the determination of key stakeholders, risks, future threats and priorities, termed as "bare minimums" by the director of the participating business, worked particularly well in managing this initial resistance, earning buy-in from all key stakeholders and interested parties in the organisation. The absence of a minimum, starter package based on organisational scale (Large, SME, $\mathrm{SMB}$ ) and/or business sector (Construction, Chemical, Medical, Automotive etc.) was noted, which would have eliminated or at least minimised the effect of this challenge, prioritising, unticking or removing the indicators that are typically not applicable to each sector (e.g. biodiversity / rights of indigenous peoples unticked as a default for the finance sector).

Resource constraints: Although the positive approach, support and intentions of the organisational leadership and ownership, the funds, manpower, management time and team availability that the business could spare for the SSCQM implementation and sustainable development was limited, negatively affecting the pace and depth of implementation and further highlighting the importance of prioritisation and risk-based approaches. The organisation was also going through other major changes at the time of the action research study including the management restructuring, relocation of the construction material packaging processes and expansion of the manufacturing facilities, further limiting the resources that could be dedicated to the SSCQM application and acting as a barrier to its complete operationalisation.

Leverage over supply base: The organisation's undeveloped relationship management practices with its suppliers and low levels of leverage over its supply chain partners was observed as a roadblock for adoption of the supply chain integration principle and dissemination of sustainability practices implemented across the supply chain. The organisation was noted in the position of a distribution hub for key players in the construction and chemical sectors, and as a minor customer of manufacturing raw material suppliers such as resin and sand suppliers, limiting its influence and power over its supply chain partners and its leverage over driving sustainability improvements across its supply chain. However, through structured relationship and portfolio management regarding its suppliers, and through exchange of valuable sustainability improvement know-how information anticipated to be captured in its journey towards sustainable development, the organisation was reflected to possess remarkable opportunities to overcome this barrier.

Culture and human resource limitations: The culture embedded in the organisation was noted as another fundamental factor to implementation of SSCQM. Particularly, a business culture that embraces continual improvement and proactiveness was noted as complimentary, assistive and promotive to SSCQM adoption. The sense of urgency, appetite for learning and willingness for improvement as shared values, resonating with a significant level of members across the organisation was noted as a major driver to application of a new management approach such as SSCQM. On the other hand, this 
would not apply to every member of the organisation, certain members resisting or choosing not to embrace this change, which is arguably a barrier to SSCQM. However, this would not be specific to SSCQM and would generally apply to most new management approaches and associated changes in most organisational settings. Due to the skills and human resource limitations in the specific region and business sectors, the difficulties associated with radical changes involving the cultural changes around the workforce and recruitment were noted as another remarkable challenge for the participating organisation.

Willingness to learn, commitment, support and engagement of leadership: Although a certain level of initial scepticism and resistance observed at the organisational leadership, which was reflected as "natural" to any new management philosophy, the open and interested approach of the leadership was paramount to the application of the synthesised SSCQM concepts and theories. The transparency, appetite and willingness of the leadership to learn, brought together a significant commitment, support and engagement both at the senior management and across the organisation to the research activity, and its associated changes towards sustainability. As the awareness level of the director and middle management increased during the course of the implementation, the level of support within the organisation to the change increased, resulting in the implementation process being embedded in the organisation and the change starting to drive itself without much input from the researcher.

Management system maturity: The organisation not only operating under the ISO 9001 management system for an established period of time but also embracing its philosophy was seen to be highly synergistic and as a catalysing factor to application of the SSCQM approach. The SSCQM approach, mainly stemming from the ISO 9001 principles was well received across the organisation and although the low levels of familiarity with the sustainability concepts being investigated for integration, the approach of how to integrate, measure and improve such concepts was highly familiar to the organisational members at all levels. Furthermore, the future aspirations of the business to fully implement and earn certification to the environmental (ISO 14001), and occupational health and safety (ISO 45001) systems were observed as motivating and driving factors for adoption of SSCQM framework, underpinned by the leadership's belief that such certification will be accelerated and/or eased by application of SSCQM.

Change facilitation and championing: Throughout the application of key steps and concepts of the SSCQM approach, the researcher acted as a "change-agent", facilitating, coordinating and structuring the implementation together with the management of the participating organisation for formulation of a systematic and clear set of actions for improvement. According to the leadership of the organisation, the presence of an academic and participative researcher highly catalysed the learning curve of the organisation, translating the GRI framework to the organisation in a way that it is meaningful, practical and interpretable by the organisation and its workforce. The director of the business named the presence of such a change facilitator and champion as "an adaptor", adapting the fairly unfamiliar sustainability concepts and associated contents to the specific business context, using the SSCQM as a medium to achieve it. It was noted that, in the business contexts of low sustainability awareness, a change facilitator and champion would positively contribute to calibration, implementation and effective operationalisation of SSCQM, that utilises the relatively new approaches of sustainability and GRI framework.

Governmental subsidisation and support: It was noticeably voiced by the leadership and ownership of the organisation a number of times during the action 
research study that, formal recognition and support from governmental and municipal institutions would highly motivate the business further in the adoption of SSCQM and any related organisational sustainability improvement initiative. It was captured that this could be in the form of both monetary (e.g. tax reduction, allocation of support funds, preferred option for governmental projects linked to sustainability improvement, subsidisation of other governmental fees payable by the firm as a result of improved sustainability performance etc.) and non-monetary terms (e.g. positive media and press, governmental award certificates etc.).

Sustainability awareness of public and market: The current sustainability awareness levels of the environment and business climate that the organisation operated in was remarkably low, resulting in a wide range of customers demanding products that are cost competitive and delivered on time, with limited or no expectations on the product sustainability and/or supplying organisation's sustainability. This naturally and historically resulted in the economic parameters being prioritised in the organisation, with relatively much less emphasis on environmental and social issues. On the other hand, this situation, which can be seen as a barrier, was identified by the organisation as "bound to change", sustainability as an imperative concept starting to receive a growing attention from both the public and the media in the region. Accordingly, the increasing public and customer sustainability awareness was recognised by the participating organisation as both a near future threat and opportunity along with emerging demand on both sustainable products and enterprises, fuelling the adoption of SSCQM and associated organisational transition towards sustainable development.

\section{Discussion}

The barriers, enablers and other key application factors observed during the implementation were supported and resonated with a number of authors in the literature that studied sustainability integration in the organisational context as presented in Table 1.

Table 1: Implementation factors observed during the action research study and supporting authors in the literature

\begin{tabular}{ll}
\hline Factor & Supporting References \\
\hline $\begin{array}{l}\text { Integration to existing management systems and } \\
\text { processes }\end{array}$ & {$[17],[18],[28]$} \\
\hline $\begin{array}{l}\text { Familiarity and awareness level of sustainability } \\
\text { concepts and terminology }\end{array}$ & {$[16]-[18],[28]-[30]$} \\
\hline Absence of a minimum starter package for GRI & {$[31]$} \\
\hline Resource constraints & {$[4],[16],[18],[28],[30]$} \\
\hline Leverage over supply base & {$[30],[32]$} \\
\hline Culture and human resource limitations & {$[17],[18],[28]-[30]$} \\
\hline Willingness to learn, commitment, support and & {$[17],[18],[28]-[30],[33]$} \\
engagement of leadership & {$[17],[18],[28],[29],[34],[35]$} \\
\hline Management system maturity & {$[28],[35]$} \\
\hline Change facilitation and championing & {$[16],[17],[28]$} \\
\hline Governmental subsidisation and support & {$[17],[18],[28],[29]$} \\
\hline Sustainability awareness of public and market & \\
\hline
\end{tabular}


In addition to the observations regarding the enablers and challenges to implementation of SSCQM, several factors and opportunities deserved further discussion. Firstly, elaborating on the earlier point regarding "the absence of a minimum GRI starter package", it was noted that there is considerable scope for further research and optimisation work with reference to the GRI framework. At the target of such an optimisation and improvement would be development of starter, medium and advanced GRI packages, tailored towards the maturity levels and sectors of the organisations.

Potential introduction of such packages would enable the organisation's to initially kick off their sustainable development journey through the GRI sustainability indicators that are the most relevant to their sector and businesses. This would highly reduce the initial resistance to change and "fear factor" that is envisaged to be experienced in many firms, guiding the organisations from the basic (starter) level of integration with a relatively limited scope into a medium level and progressively into a final level of integration, where all GRI indicators are integrated and mechanisms in place for improvement (as indicated with "world class" level of maturity in the SSCQM approach). A similar observation was noted by Fonseca (2010) [31], that outlined the "demanding" nature of the GRI framework, discussing that "setting the bar too high with too many indicators possesses the risk of inhibiting the voluntary uptake of the framework and adding more requirements on 'what' and 'how' to report is delicate".

An anticipated additional impact of this could also be the steering of business sectors towards sectoral sustainability norms, driving all sectors towards a collective improvement environment. Through this resolution, the implementation pace of all sustainability initiatives incorporating GRI including the SSCQM would be arguably accelerated. This implies a widespread and comprehensive sectoral and organisational scale-based data collection towards both capturing business sector and organisation scale specific indicators, determining bare minimum indicators for the same, and revealing other sustainability indicators that might be context-specific and not yet incorporated into the GRI framework.

Ultimately, prior to implementation, a structured training and exchange of information session with the key stakeholders on sustainability (basic concepts and terminology) and GRI framework was noted as highly beneficial, clarifying any misperceptions, setting out a common understanding ground and highly contributing to the effective communication of SSCQM philosophy, which were established as key to a smooth business transition towards the "sustainable" change.

\section{Conclusions}

In this research, enablers, barriers and challenges to a QM and SCM based approach to sustainability (SSCQM) was studied through an action research study held at a manufacturing organisation. The key parameters observed included; integration to existing management systems and processes, familiarity and awareness level of sustainability concepts and terminology, absence of a minimum starter package for GRI, resource constraints, leverage over supply base, culture and human resource limitations, willingness to learn, commitment, support and engagement of leadership, management system maturity, change facilitation and championing, governmental subsidisation and support, and sustainability awareness of public and market.

A significant future research and refinement opportunity was established regarding the GRI framework through identification of organisational scale and sector specific packages, along with incorporation of a maturity based approach, guiding organisations through a basic, medium and advanced levels of adoption, as opposed to exposing the 
framework to industrial resistance due to the remarkable learning curve associated, and the long list of indicators included in the GRI framework.

The action research study was undertaken on a single case (an organisation), in a particular region (Cyprus), operating in specific business sectors (construction and chemical), which point towards a contextual research limitation, and hence our findings are recommended to be further studied in other manufacturing sectors and contexts.

\section{References}

[1] J. Elkington, Enter the Triple Bottom Line. Routledge, 2013.

[2] A. Rajeev, R. K. Pati, S. S. Padhi, and K. Govindan, "Evolution of sustainability in supply chain management: A literature review," J. Clean. Prod., vol. 162, pp. 299-314, 2017, doi: 10.1016/j.jclepro.2017.05.026.

[3] Z. N. Ansari and M. N. Qureshi, "Sustainability in supply chain management: An overview," IUP J. Supply Chain Manag., vol. 12, no. 2, pp. 24-46, 2015, Accessed: Aug. 08, 2017. [Online]. Available: http://search.proquest.com/openview/69ba3247455e4d164e14eb14aac961a6/1?pqorigsite $=$ gscholar $\& \mathrm{cbl}=2030007$.

[4] S. Seuring and M. Müller, "From a literature review to a conceptual framework for sustainable supply chain management," J. Clean. Prod., vol. 16, no. 15, pp. 1699-1710, 2008, doi: 10.1016/j.jclepro.2008.04.020.

[5] A. Williams, S. Kennedy, F. Philipp, and G. Whiteman, "Systems thinking: A review of sustainability management research," J. Clean. Prod., vol. 148, pp. 866-881, 2017, doi: 10.1016/j.jclepro.2017.02.002.

[6] A. Bastas, "Sustainable Manufacturing Technologies: A Systematic Review of Latest Trends and Themes," Sustainability, vol. 13, no. 8, p. 4271, Apr. 2021, doi: 10.3390/su13084271.

[7] United Nations, "About the Sustainable Development Goals - United Nations Sustainable Development," 2015. https://www.un.org/sustainabledevelopment/sustainable-development-goals/ (accessed Jan. 01, 2019).

[8] M. Terziovski and P. Hermel, "The Role of Quality Management Practice in the Performance of Integrated Supply Chains: A Multiple Cross-Case Analysis," Qual. Manag. J., vol. 18, pp. 10-25, 2011, Accessed: Jul. 29, 2017. [Online]. Available: http://search.proquest.com/openview/33d0a4ed6c81a72a309a6ddfd2e5db12/1?pqorigsite $=$ gscholar $\&$ cbl $=31933$.

[9] V. Siva, I. Gremyr, B. Bergquist, R. Garvare, T. Zobel, and R. Isaksson, "The support of Quality Management to sustainable development: a literature review," J. Clean. Prod., vol. 138, pp. 148157, 2016, doi: 10.1016/j.jclepro.2016.01.020.

[10] A. Bastas and K. Liyanage, "ISO 9001 and Supply Chain Integration Principles Based Sustainable Development: A Delphi Study," Sustain. 2018, Vol. 10, Page 4569, vol. 10, no. 12, p. 4569, 2018, doi: 10.3390/SU10124569.

[11] A. Ashby, M. Leat, and M. Hudson-Smith, "Making connections: a review of supply chain management and sustainability literature," Supply Chain Manag. An Int. J., vol. 17, no. 5, pp. 497516, 2012, doi: 10.1108/13598541211258573.

[12] K. Govindan, S. G. Azevedo, H. Carvalho, and V. Cruz-Machado, "Impact of supply chain management practices on sustainability," J. Clean. Prod., vol. 85, pp. 212-225, 2014, doi: 10.1016/j.jclepro.2014.05.068.

[13] A. Bastas and K. Liyanage, "Sustainable supply chain quality management: A systematic review," J. Clean. Prod., vol. 181, no. C, pp. 726-744, 2018, doi: 10.1016/j.jclepro.2018.01.110.

[14] A. Bastas and K. Liyanage, "Integrated quality and supply chain management business diagnostics for organizational sustainability improvement," Sustain. Prod. Consum., vol. 17, no. C, pp. 11-30, 2019, doi: 10.1016/J.SPC.2018.09.001.

[15] A. Bastas and K. Liyanage, "Setting a framework for organisational sustainable development," Sustain. Prod. Consum., vol. 20, pp. 207-229, 2019, doi: 10.1016/j.spc.2019.06.005.

[16] N. Bhanot, P. V. Rao, and S. G. Deshmukh, "Enablers and barriers of sustainable manufacturing: Results from a survey of researchers and industry professionals," in Procedia CIRP, Jan. 2015, vol. 29, pp. 562-567, doi: 10.1016/j.procir.2015.01.036.

[17] A. Neri, E. Cagno, G. Di Sebastiano, and A. Trianni, "Industrial sustainability: Modelling drivers and mechanisms with barriers," J. Clean. Prod., vol. 194, pp. 452-472, 2018, doi: 10.1016/j.jclepro.2018.05.140.

[18] A. Trianni, E. Cagno, and A. Neri, "Modelling barriers to the adoption of industrial sustainability measures," J. Clean. Prod., vol. 168, pp. 1482-1504, Dec. 2017, doi: 10.1016/j.jclepro.2017.07.244. 
[19] L. C. Giunipero, R. E. Hooker, and D. Denslow, "Purchasing and supply management sustainability: Drivers and barriers," J. Purch. Supply Manag., vol. 18, no. 4, pp. 258-269, Dec. 2012, doi: 10.1016/j.pursup.2012.06.003.

[20] M. del M. Alonso-Almeida, J. Llach, and F. Marimon, "A closer look at the 'Global Reporting Initiative' sustainability reporting as a tool to implement environmental and social policies: A worldwide sector analysis," Corp. Soc. Responsib. Environ. Manag., vol. 21, no. 6, pp. 318-335, 2014, doi: 10.1002/csr.1318.

[21] GRI, "Sustainability Reporting," GRI Reporting Standards, 2021. https://www.globalreporting.org/information/sustainability-reporting/ (accessed Dec. 29, 2018).

[22] K. Lewin, "Action Research and Minority Problems," J. Soc. Issues, vol. 2, no. 4, pp. 34-46, Nov. 1946, doi: 10.1111/j.1540-4560.1946.tb02295.x.

[23] P. Checkland and S. Holwell, "Action Research: Its Nature and Validity," Syst. Pract. Action Res., vol. 11, no. 1, pp. 9-21, 1998, doi: 10.1023/A:1022908820784.

[24] C. MacDonald, "Understanding Participation Action Research: A Qualitative Research Methodology Option," Can. J. Action Res., vol. 13, no. 2, pp. 34-50, 2012, doi: 10.1209/0295-5075/78/26002.

[25] J. Savage, "Participative observation: Standing in the shoes of others?," Qual. Health Res., vol. 10, no. 3, pp. 324-339, May 2000, doi: 10.1177/104973200129118471.

[26] G. Vinten, "Participant Observation: A Model for Organizational Investigation?," Journal of Managerial Psychology, vol. 9, no. 2. MCB UP Ltd, pp. 30-38, Apr. 12, 1994, doi: $10.1108 / 02683949410059299$.

[27] E. Barnett-Page and J. Thomas, "Methods for the synthesis of qualitative research: a critical review," BMC Med. Res. Methodolgy, vol. 9, p. 59, 2009, Accessed: Aug. 10, 2017. [Online]. Available: https://bmcmedresmethodol.biomedcentral.com/articles/10.1186/1471-2288-9-59.

[28] N. Blanco-Portela, J. Benayas, L. R. Pertierra, and R. Lozano, "Towards the integration of sustainability in Higher Education Institutions: A review of drivers of and barriers to organisational change and their comparison against those found of companies," J. Clean. Prod., vol. 166, pp. 563578, 2017, doi: 10.1016/j.jclepro.2017.07.252.

[29] R. A. George, A. K. Siti-Nabiha, D. Jalaludin, and Y. A. Abdalla, "Barriers to and enablers of sustainability integration in the performance management systems of an oil and gas company," $J$. Clean. Prod., vol. 136, pp. 197-212, 2016, doi: 10.1016/j.jclepro.2016.01.097.

[30] S. Al Zaabi, N. Al Dhaheri, and A. Diabat, "Analysis of interaction between the barriers for the implementation of sustainable supply chain management," Int. J. Adv. Manuf. Technol., vol. 68, no. 1-4, pp. 895-905, 2013, doi: 10.1007/s00170-013-4951-8.

[31] A. Fonseca, "Barriers to Strengthening the Global Reporting Initiative Framework : Exploring the perceptions of consultants, practitioners, and researchers," 2nd Can. Sustain. Indic. Netw. Conf. Account. Through Meas., no. March 2010, pp. 1-27, 2010, [Online]. Available: http://www.csinrcid.ca/downloads/csin_conf_alberto_fonseca.pdf.

[32] S. Seuring, J. Sarkis, $\bar{M}$. Müller, and P. Rao, "Sustainability and supply chain management - An introduction to the special issue," J. Clean. Prod., vol. 16, no. 15, pp. 1545-1551, 2008, doi: 10.1016/j.jclepro.2008.02.002.

[33] S. Seidel, C. Pimmer, J. Recker, and J. vom Brocke, "Enablers and Barriers to the Organizational Adoption of Sustainable Business Practices," in Proceeding of the 16th Americas Conference on Information Systems : Sustainable IT Collaboration around the Globe, 2010, no. August, pp. 12-15, doi: $10.2495 /$ UT150491.

[34] S. Engert, R. Rauter, and R. J. Baumgartner, "Exploring the integration of corporate sustainability into strategic management: A literature review," J. Clean. Prod., vol. 112, pp. 2833-2850, 2016, doi: 10.1016/j.jclepro.2015.08.031.

[35] S. Witjes, W. J. V. Vermeulen, and J. M. Cramer, "Exploring corporate sustainability integration into business activities. Experiences from 18 small and medium sized enterprises in the Netherlands," J. Clean. Prod., vol. 153, pp. 528-538, 2017, doi: 10.1016/j.jclepro.2016.02.027. 